\title{
$\beta$ adrenoceptor density in the donor heart: a guide to prognosis?
}

\author{
Michael R Chester, Aham A Amadi, David B Barnett
}

\begin{abstract}
Background-Failure of the donor (graft) heart is the main cause of mortality in the first month after orthotopic cardiac transplantation. In a preliminary study marked downregulation of cardiac $\beta$ adrenoceptor density was found in apparently normal donor hearts of recipients who developed severe cardiac failure soon after implantation. Cardiac $\beta$ adrenoceptors are an important factor in the development of cardiac failure in the human heart. The aim of this study therefore was to determine whether fatal graft failure in the first month after transplantation is associated with downregulation of $\beta$ adrenoceptor density in the donor heart.
\end{abstract}

Patients and methods-Right ventricular endomyocardial biopsy specimens were taken from consecutive adult donor patients immediately before implantation. A previously described radioligand binding method was used to determine $\beta$ adrenoceptor density in consecutive patients who developed fatal graft failure and died within 1 month of transplantation and in a group of control donors transplanted during the same period.

Results-Perioperative fatal graft failure developed in 13 patients. Forty one specimens from donor hearts that were transplanted into recipients who did not develop fatal graft heart failure formed the control group. There were no systematic differences in donor or recipient characteristics between the graft heart failure and control groups. In particular donor catecholamine requirement and recipient pulmonary vascular resistance did not differ between groups. Total $\beta$ adrenoceptor density was reduced in the fatal graft heart failure group compared with that in the controls $(13.4$ (7) $\mathrm{fmol} / \mathrm{mg}$ $v 21$ (7) $\mathrm{fmol} / \mathrm{mg} ; P<0.01)$. There was a positive correlation between $\beta$ adrenoceptor density in the donor heart and time to death in the graft heart failure group $\left(r^{2}=0.3, P<0.05\right)$. The $\beta$ adrenoceptor binding affinity (Kd) did not differ between the graft failure group and the controls (47 (6) pM $v 44$ (7) $\mathrm{pM}$ ).

Conclusion-The development of perioperative fatal cardiac failure after orthotopic cardiac transplantation is associated with downregulation of $\beta$ adrenoceptors in the donor heart before implantation.

(Br Heart F 1995;73:540-543)
Keywords: human cardiac transplantation; $\beta$ adrenoceptor downregulation; cardiac failure

Graft heart failure unrelated to rejection, infection, or raised pulmonary vascular resistance in the recipient is the main cause of death in the perioperative period after orthotopic transplantation. ${ }^{1}$ During the development of a new method for analysing $\beta$ adrenoceptor binding affinity in human myocardial biopsy tissue, ${ }^{2}$ we observed that $\beta$ adrenoceptor density was markedly reduced in apparently normal donor hearts of recipients who unexpectedly developed severe intractable graft heart failure that was unresponsive to escalating doses of catecholamines and died soon after implantation. There were no obvious differences between successful and poor outcome donors, moreover, all donors satisfied the criteria for transplantation, and the hearts seemed normal at harvesting. Downregulation of $\beta$ adrenoceptor in the human heart correlates with the degree of cardiac failure and prognosis. ${ }^{34}$ We therefore set out to test the hypothesis that fatal graft cardiac failure after cardiac transplantation is associated with $\beta$ adrenoceptor downregulation in the donor heart.

\section{Patients and methods}

The study population was derived from consecutive patients over a 3 year period who underwent conventional orthotopic cardiac transplantation at Harefield Hospital using hearts from brain dead donors. Two to five right ventricular endomyocardial biopsy specimens were routinely taken from each donor heart immediately before implantation, and were immediately frozen in liquid nitrogen, and stored at $-70^{\circ} \mathrm{C}$.

The clinical details of the patients who were analysed were obtained from the medical records and hospital database.

\section{DONOR DETAILS}

The donor clinical details included age, sex, cause of death, and ventilation and ischaemic times. In addition, the dosage and duration of any catecholamine treatment were recorded. Haemodynamic indices at the time of transplantation assessment were likewise obtained from the notes and confirmed where possible from direct recordings. Standard electrocardiograms (ECGs) were performed in each case and assessed by an experienced operator. ECGs were defined as normal or abnormal according to the presence of $Q$ waves, $S T$ or $\mathrm{T}$ waves. Terital Medical Scho Tooting, London SW 17 ORE. 


\section{RECIPIENT}

Recipient details included age, sex, underlying cardiac diagnosis, use of inotropic support before transplantation, and outcome. Where available pulmonary haemodynamic indices were obtained as close to the time of transplantation as possible.

\section{OUTCOME DEFINITIONS}

Patients were grouped according to the presence or absence of a clinical diagnosis of death primarily caused by intractable graft failure that was unrelated to tissue rejection within 31 days of transplantation - that is, perioperative. The death certificates (where appropriate), notes, and especially the intensive care records were reviewed blind to the $\beta$ adrenoceptor data. The diagnosis of primary cardiac failure was considered firm if made by a consultant experienced in transplantation management. Otherwise, the diagnosis was made, in the absence of bleeding, tissue rejection, or septicaemia, if there was clear evidence of intractable haemodynamic deterioration despite inotropic support and associated worsening radiological pulmonary oedema or increased pulmonary artery wedge pressure, and the patient died without recovering. Thus, recipients in whom the primary cause of death was considered to be other than cardiac failure were included in the control group.

\section{METHODS}

Membrane preparation and the radioligand binding method have been described previously. ${ }^{5}$

Protein concentrations were assayed in duplicate using the Lowry method with bovine serum albumin as standard. ${ }^{6}$

$\beta$ adrenoceptor density and the equilibrium dissociation constant $(\mathrm{Kd})$ were analysed in all specimens using non-linear regression

Table 1 Clinical features of donor patients

\begin{tabular}{lcc}
\hline & $\begin{array}{c}\text { Graft heart failure } \\
(n=13)\end{array}$ & $\begin{array}{c}\text { Controls } \\
(n=41)\end{array}$ \\
\hline Age (y) & $36(11)$ & $31(9)$ \\
BP & $111(20)$ & $109(17)$ \\
Ventilation time & $2 \cdot 7(1 \cdot 1)$ & $3 \cdot 4(1 \cdot 9)$ \\
Proportion on DA (\%) & 50 & 52 \\
Dopamine infusion rate† & $1 \cdot 3(2 \cdot 5)$ & $3 \cdot 0(5 \cdot 3)$ \\
Proportion on inotropes (\%) & 15 & 11 \\
Infusion rate & $3 \cdot 2(7 \cdot 4)$ & $2 \cdot 1(5 \cdot 3)$ \\
IT (min) & $150(16)$ & $163(7)$ \\
\hline
\end{tabular}

$\mathrm{BP}=$ Systemic systolic blood pressure at the time of assessment for transplantation $(\mathrm{mm} \mathrm{Hg})$. VT $=$ Ventilation time (days), DA, dopamine. + proportion of patients receiving therapy at the time of organ harvesting. Dopamine infusion rate $(\mu \mathrm{g} / \mathrm{kg} / \mathrm{min})$ over the $24 \mathrm{~h}$ before organ harvesting fatecholamine (usually dobutamine) infusion rate $(\mu \mathrm{g} / \mathrm{kg} / \mathrm{min})$ over the $24 \mathrm{~h}$ before organ harvesting IT, Ischaemic time. Values are mean (SD). There were no significant differences between graft failure and control donors.

Table 2 Donor characteristics

\begin{tabular}{llllll}
\hline & \multicolumn{2}{l}{ Cause of death } \\
\cline { 2 - 5 } & $\begin{array}{l}\text { Cerebrovascular } \\
\text { accident }\end{array}$ & Head injury & Other * & $\begin{array}{l}\text { Gender } \\
\text { Male }\end{array}$ \\
\hline Controls $(\mathrm{n}=41)$ & $21(51)$ & $16(39)$ & $4(10)$ & $24(59)$ \\
Graft heart failure group $(\mathrm{n}=13)$ & $7(54)$ & $5(38)$ & $1(8)$ & $9(69)$ \\
\hline
\end{tabular}

Values in parentheses are percentages. CVA, cerebrovascular accident HI, Head injury. There were no intergroup differences. ${ }^{\star}$ Other includes asphyxiation. analysis of the untransformed saturation binding data (Inplot; GraphPAD, San Diego). In each case all the data points were included for non-linear analysis.

\section{REAGENTS}

(-)-Pindolol labelled with iodine-125 with a theoretical specific activity of 2175 $\mathrm{cpm} / \mathrm{mmol}$ was prepared by the method described by Barovski and Brooker ${ }^{7}$ using sodium iodide-125 (IMS 30) obtained from Amersham. (-)-Pindolol and CGP 20712 A were generously donated by Sandoz and Ciba, respectively.

\section{STATISTICAL ANALYSIS}

Comparisons between groups were performed using the Student's $t$ test for continuous variables and the $\chi^{2}$ test for discrete variables. All comparisons were two tailed and $\mathrm{P}<0.05$ was considered significant. Results are given as mean (SD) unless stated otherwise.

\section{Results}

Biopsy specimens from 54 donor hearts were analysed. Thirteen consecutive donor hearts were transplanted into recipients who died within 31 days of implantation; graft heart failure unrelated to rejection was considered to be the main cause of death. The remaining 41 specimens were collected during the same period from donor hearts that were transplanted into recipients who did not develop fatal graft failure and formed the control group. Two patients in the control group died in the perioperative period; one with septicaemia and the other with severe rejection.

\section{DONOR CHARACTERISTICS}

There were no differences between the graft failure and control donors with respect to age, cause of death, and ischaemic or ventilation times (table 1). All donors analysed were considered "normal" on the basis of history or examination by the referring physician. In addition, each donor heart was described as "normal" in the surgical operation note, by the harvesting surgeon, at the time of explantation. Dobutamine was occasionally administered for hypotensive episodes and low dose dopamine was frequently administered for renoprotection but there was no difference between controls and patients with donor hearts associated with a poor outcome (table 1). There were no intergroup differences with respect to gender and cause of death (table 2). No patient had evidence of $Q$ wave myocardial infarction. Minor ECG abnormalities, usually anterior $T$ wave inversion, were relatively common in each group but did not differ between groups.

\section{RECIPIENT CHARACTERISTICS}

None of the recipient characteristics assessed differed between the graft failure group and controls. Pulmonary vascular resistance was $2 \cdot 2$ (1) Wood units in the controls and $2 \cdot 4$ (1) Wood units in the graft failure group ( $P=$ NS). Three of the control recipients received 


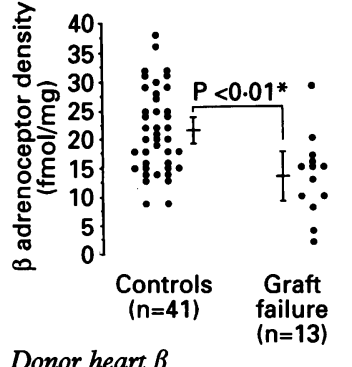

heart $\beta$ adrenoceptor density and perioperative fatal graft heart failure. Bars are means and $95 \%$ confidence intervals. *Intergroup differences were tested using Student's $t$ test and the Wilcoxon rank sum test. catecholamines at the time of transplantation. Two control recipients received renal dose dopamine alone and a third additional dobutamine at a rate of $<10 \mu \mathrm{g} / \mathrm{kg} / \mathrm{min}$ during the $24 \mathrm{~h}$ before transplantation. None of the recipients whose donor heart developed graft failure received preoperative mechanical or inotropic support.

\section{$\beta$ ADRENOCEPTOR DENSITY}

Total $\beta$ adrenoceptor density was reduced in the graft failure group compared with that in the controls (13.4 (7) fmol/mg $v 21.5$ (7) $\mathrm{fmol} / \mathrm{mg}, \mathrm{P}<0.01)$. The figure shows individual data points. The $\beta$ adrenoceptor binding affinity (Kd) did not differ between the graft failure group and controls (47 (6) pM v 44(7) $\mathrm{pM})$. There was no relation between ischaemic time and $\beta$ adrenoceptor density ( $y$ $=0.01 \mathrm{x}+18, r^{2}=0.01, \mathrm{P}=0.65$ ).

There was a positive correlation between donor $\beta$ adrenoceptor density and time to death in the graft heart failure group $(\mathrm{y}=1 \mathrm{x}$ $\left.+7, r^{2}=0.3, P=0.044\right)$.

\section{Discussion}

This study, based on a chance observation in a previous study, ${ }^{5}$ shows for the first time that the development of intractable graft failure and death soon after transplantation is associated with downregulation of $\beta$ adrenoceptor density in the right ventricular endomyocardium of brain dead donor hearts before implantation.

Graft heart failure is a major cause of perioperative mortality after cardiac transplantation. ${ }^{1}$ Several studies have identified abnormalities in the recipient, such as raised pulmonary vascular resistance and inotropic requirement, that are associated with graft failure and poor outcome after implantation. ${ }^{89}$ Darracott-Cankovic and colleagues ${ }^{10}$ have shown that apparently "normal" donor hearts may be functionally impaired. Furthermore, these authors observed a correlation between myocardial injury in the donor heart at transplantation and increased early mortality after transplantation. ${ }^{11}$ All donor hearts in our study were obtained from previously normal patients with brain death. Experimental models have demonstrated that brain death can induce myocardial damage through over activation of the sympathoadrenergic pathway. ${ }^{12}$ There is extensive clinical evidence that "sympathetic storm" after brain damage also produces myocardial injury in humans ${ }^{13-15}$ and is accompanied by excess catecholamine release. ${ }^{16}$ Overall downregulation of cardiac $\beta$ adrenoceptor after increased sympathetic stimulation and catecholamine exposure is well recognised in humans and is associated with impaired systolic function in heart failure. ${ }^{31718}$ Thus the findings in our study are consistent with the notion that donor hearts that developed graft failure may have been exposed to excess catecholamines before explantation. Whether this relates to a centrally mediated "sympathetic storm" after brain death is speculative. Certainly, there was no obvious clinical or electrocardiographic evidence of such a process operating in the graft failure group in our study. Selective $\beta$ adrenoceptor subtype blockade during cerebral injury has shown that centrally mediated myocardial damage is predominantly through the $\beta_{1}$ adrenoceptor subtype. ${ }^{19}$ Such a mechanism might be expected to selectively downregulate $\beta_{1}$ adrenoceptors. We assessed $\beta_{1}$ and $\beta_{2}$ adrenoceptor subtype density in a few specimens (five of the graft heart failure group and 13 of the controls) using CGP 20712A as described previously..$^{20}$ There was a trend towards a relative reduction in the $\beta_{1}$ subtype in the graft failure group (56 (4)\%) compared with that in the controls (65 (3)\%) $(P=0.08)$.

In clinical practice intensive care patients rarely die from cardiac failure alone. Multisystem failure usually intervenes in extremis, as was the case in our patients. It is therefore highly unlikely that downregulation of $\beta$ adrenoceptor per se can account for the increased mortality in the graft failure group. Indeed, there is considerable overlap in $\beta$ adrenoceptor density between the graft failure group and the controls. Furthermore, the observed positive correlation between $\beta$ adrenoceptor density and survival time in the graft failure group should be interpreted with caution because of the relatively small numbers of patients with fatal graft failure. Whether downregulation of $\beta$ adrenoceptor has a role in the development of graft failure or whether downregulation reflects a pathological process in the donor that contributes to mortality is speculative.

The absolute values in the literature for $\beta$ adrenoceptor density in normal hearts vary considerably. There was possibly a loss of receptors in our study during the period between organ harvesting and biopsy procurement (ischaemic time). There was no correlation, however, between ischaemic time and $\beta$ adrenoceptor density in this study and we have previously found that $\beta$ receptor density is stable in iced cardioplegia solution for up to $4 \mathrm{~h}$ in rat heart. Despite differences in tissue preparation and analytical technique our results approximate to the values obtained by Fowler $e t a l^{3}$ and Denniss et $a l^{17}$ in similar tissues $(19.7$ and $21.4 \mathrm{fmol} / \mathrm{mg}$, respectively). It is not acceptable to perform multiple biopsies from different regions of donor hearts during routine transplantation procedures. Although multiple, the biopsy specimens taken in our study were mostly from the right side of the interventricular septum and whether such samples are representative of the whole heart is not known. We observed, however, that $\beta$ adrenoceptors were homogeneously distributed in five unused normal donor hearts (unpublished observations). The use of $\beta$ adrenoceptor agonists in the donor hearts did not differ between groups and is unlikely to explain $\beta$ adrenoceptor downregulation; however, the number of patients in our study is too small to exclude this possibility.

This study was designed with an a priori hypothesis that was based on preliminary 
observations from a different data set and relied on clinical details and biopsy specimens that were collected routinely. The relatively small number of patients in the study and control groups, along with replication of clinical data in the patients' general medical records, transplantation note records, and the clinical database, ensured completeness of data collection.

\section{LIMITATIONS}

The available tissue was limited and we therefore assessed only $\beta$ adrenoceptor density. It is not known whether responsiveness of the $\beta$ adrenoceptor pathway was also altered in patients with donor hearts associated with a poor outcome.

Clinical and haemodynamic assessment of donor patients in our study was limited. Donor hearts with a poor outcome may possibly have already started to fail subclinically before harvesting. Future prospective studies should include detailed clinical and haemodynamic evaluation of the donor as well as the recipient.

\section{Conclusion}

This study has demonstrated a hitherto unrecognised association between downregulation of $\beta$ adrenoceptor density in the apparently normal donor heart and the development of fatal graft heart failure after implantation. The study shows that better methods of evaluation to improve the prognosis of recipients are needed and that further research in the area of donor heart evaluation is warranted. Finally, the study brings into question the validity of using unused brain dead donor hearts as "normal" controls in studies of $\beta$ adrenoceptor function and regulation in the human heart. ${ }^{451721}$

We thank Professor Sir Magdi $\mathrm{H}$ Yacoub for allowing us access to the patients analysed in this study. MRC was supported by a British Heart Foundation research fellowship grant.

1 Kriett JM, Kaye MP. The Registry of the International Society for Heart Transplantation: Seventh Official Report-1990. I Heart Transplant 1990;9:323-30.

2 Chester MR. $\beta$-adrenoceptor subtypes and catecholamines in the transplanted human heart [thesis]. Leicester: Leicester University, 1993:60-8.
3 Fowler MB, Laser JA, Hopkins GL, Minobe W, Bristow MR. Assessment of the beta adrenergic pathway in the MR. Assersment of the beta adrenergic pathway in the intact failing human heart: progressive down regulation and subsensitivity

4 Ginsberg R, Bristow MR, Billingham ME, Stinson EB, Schroeder JS, Harrison DC. Study of the normal and failing isolated human heart: decreased response of the failing heart to isoproterenol. Am Heart $\mathcal{F}$ 1983;106: 535-40.

5 Chester MR, Madden B, Barnett D, Yacoub MH. The density of $\beta_{1}$ - and $\beta_{2}$ - adrenergic receptor subtypes in endomyocardial biopsies in the first thirteen months post orthotopic transplantation. Br F Clin Pharmacol 1992;33: 417-22.

6 Lowry OH, Rosenbrough NJ, Farr AL, Randall R. Protein measurement with the Folin phenol reagent. $f$ Biol Chem 1951;193:265-8.

7 Barovski K, Brooker G. (-)- [125I]-iodopindolol, a new highly selective radioiodinated beta- adrenergic receptor antagonist: measurement of beta-receptors on intact rat antagonist: measurement of beta-receptors on intact rat

8 Costard-Jackle A, Hill I, Shroeder JS, Fowler MB. The influence of preoperative patient characteristics on early influence of preoperative patient characteristics on early
and late survival following cardiac transplantation. and late survival following

9 Walhers T, Cremer J, Fiequth HG, Dammenhavn L, Albes J, Schafers HJ. Donor heart-related variables and early mortality after heart transplantation. $\mathcal{F}$ Heart Lung Transplant 1991;10:22-7.

10 Darracott-Cankovic S, Wheeldon D, Cory-Pearce $R$ Wallwork J, English TAH. Biopsy assessment of 50 hearts during transplantation. F Thorac Cardiovasc Surg 1987;93:95-102.

11 Darracott-Cankovic S, Stovin PGI, Wheeldon D, Wallwork J, Wells FC, English TAH. Effect of donor heart damage on survival after transplantation. Eur $\mathcal{F}$ Cardiothorac Surg 1989;3:525-32.

12 Novitzky D, Wicomb WN, Cooper DKC, Rose AG Fraser RC, Barnard CN. Electrocardiographic, haemodynamic and endocrine changes occuring during experimental brain death in the Chacma baboon. Heart Transplant 1984;4:63-9.

13 Connor RCR. Heart damage associated with intracranial lesions. $\operatorname{Br} \mathcal{f}$ Med 1968;3:29-31.

14 Yamour BJ, Sridaharan MR, Rice JF, Flowers NC Electrocardiographic changes in cerebrovascular haemorrhage. Am Heart f 1980;99:294-300.

15 Smith RP, Tomlinson BE. Subendocardial haemorrhages associated with intracranial lesion. $\mathcal{F}$ Pathol Bact 1954 68: 327-9.

16 Myers MG, Norris JW, Hachinski VC, Sole MJ. Plasma norepinephrine in stroke. Stroke $1981 ; 12: 200-5$.

17 Denniss AR, Marsh JD, Quigg RJ, Gordon JB, Colucci WS. Beta-adrenergic receptor number and adenylate cyclase function in denervated transplanted and cyclase function in denervated transplanted and car1028-34.

18 Bristow MR, Hershberger RE, Port JD, Minobe W, Rasmussen R. Beta 1 and beta 2-adrenergic receptormediated adenylate cyclase stimulation in nonfailing and failing human ventricular myocardium. Mol Pharmacol failing human ven

19 Kolin A, Brezina A, Lewis AJ, Norris JW. Quantitative evaluation of myocardial injury induced by acute cerebral ischaemia and its prevention by beta 1 adrenergic blockade: an ultrastructural morphometric study. $\mathrm{Br} \mathcal{F}$ Exp Pathol 1989;70:659-67.

20 Chester MR, Amadi AAA, Barnett DB, Yacoub MH Post- orthotopic transplantation cardiac failure is associated with $\alpha 1$-adrenoceptor downregulation in the donor heart. Circ Res 1992;86:1420.

21 Bristow MR, Ginsburg R, Minobe W, Cubiciotti RS, Sageman WS, Lurie KG, et al. Decreased catecholamine sensitivity and beta adreneroic receptor density in failing human hearts. N Engl F Med 1982;307:205-11. 